\title{
An attempt to infer information on planetary wave by analyzing sporadic $E$ layers observations
}

\author{
Xiaomin Zuo ${ }^{1}$, Weixing Wan ${ }^{2}$, and Guangxin $\mathrm{Zhao}^{3}$ \\ ${ }^{1}$ School of Mathematics and Physics, China University of Geosciences, Wuhan 430074, China \\ ${ }^{2}$ Institute of Geology and Geophysics, Chinese Academy of Sciences, Beijing 100029, China \\ ${ }^{3}$ School of Sciences, Wuhan University of Science and Engineering, Wuhan 430073, China
}

(Received March 17, 2009; Revised June 8, 2009; Accepted June 29, 2009; Online published November 30, 2009)

\begin{abstract}
In this paper we presented two typical global 6-day planetary wave oscillations occurring in sporadic $E$ layers. By analyzing the $f_{\mathrm{o}} E_{\mathrm{s}}$ time series observed from several ionosonde stations on the basis of the methods suggested by Haldoupis and Pancheva (2002), we computed estimates for the PW propagation direction, zonal wave number and phase velocity. We obtained results that the 6-day PW, with zonal wave number about 1, propagates westward, which are in agreement with those reported from radar and satellite neutral wind MLT measurements. The results provide experimental evidence for a close relationship between PWs and midlatitude $E_{\mathrm{s}}$. In addition, the study proves the validity of $E_{\mathrm{s}}$ observations measured routinely and rather reliably with a dense global network of digital ionosondes used as an alternative means of studying large-scale neutral atmospheric dynamics in the MLT region.
\end{abstract}

Key words: Sporadic $E$ layers, planetary waves, MLT dynamics.

\section{Introduction}

In general, the main factor involved in midlatitude sporadic $E\left(E_{\mathrm{s}}\right)$ formation is vertical neutral wind shears, associated with tides and/or gravity waves, which can compress the long-living metallic ions into a thin layer (e.g., see review articles by Whitehead, 1989; Mathews, 1998). Meanwhile, planetary waves (PWs) also play an important role on the formation of midlatitude $E_{\mathrm{s}}$, as having been reported in many studies. Tsunoda et al. (1998) and Voiculescu et al. (1999) were the first to give evidence for planetary wave effects on midlatitide backscatter and the sporadic $E$ layer occurrence. Furthermore, Voiculescu et al. (2000) analyzed measurements of midlatitude $E$ region coherent backscatter obtained during four summers with SESCAT (Sporadic E SCATter experiment), a $50 \mathrm{MHz}$ Doppler radar system operating in Crete, Greece, concurrent ionosonde recordings from the same ionospheric volume obtained with a CADI (Canadian Advanced Digital Ionosonde) for one of these summers and simultaneous neural wind data from the mesopause region around $95 \mathrm{~km}$, measured in Germany. The results suggested that planetary wave effect on sporadic $E$ is a viable option, which introduces a new element into the physics of midlatitude $E$ region layering phenomena.

The first direct experimental evidence in favor of a PW role on $E_{\mathrm{s}}$ generation was provided by Haldoupis and Pancheva (2002). They analyzed $f_{\mathrm{o}} E_{\mathrm{s}}$ data from a number of ionosonde stations covering a large longitudinal sector and found that a strong 7-day period oscillation in $E_{\mathrm{s}}$ was closely related with a simultaneous 7-day PW present

Copyright (c) The Society of Geomagnetism and Earth, Planetary and Space Sciences (SGEPSS); The Seismological Society of Japan; The Volcanological Society of Japan; The Geodetic Society of Japan; The Japanese Society for Planetary Sciences; TERRAPUB. in the mesosphere and lower thermosphere (MLT region) winds, which was detected with meteor radars and from space with satellites. Recently, Zuo and Wan (2008) also reported the evidence in the Wuhan ionosonde and MLT neutral wind observations on the existence of a close relationship between planetary wave oscillations and variations in sporadic $E$ layer occurrence. The authors further confirmed that PW play an important role in the formation of mid-latitude sporadic $E$ layers.

A possible mechanism for the explanation of the PW effects on $E_{\mathrm{s}}$ was proposed by Shalimov et al. (1999). This was followed by a theoretical model (Shalimov and Haldoupis, 2002) postulating a direct role for the PWs on $E_{\mathrm{s}}$ formation which relied on large-scale accumulation of metallic ions in the midlatitude $E$ region ionosphere driven by PW horizontal wind shears. While Pancheva et al. (2003) and Haldoupis et al. (2004) suggested that the effects of PW on $E_{\mathrm{s}}$ were indirect through the PW modulation of the diurnal and semidiurnal tides in the MLT region. Also, the findings of Zuo and Wan (2008) favor an indirect PW role on $E_{\mathrm{s}}$ through a nonlinear process of PW modulation of the tidal wind amplitudes, which in line with the studies of Pancheva et al. (2003) and Haldoupis et al. (2004).

The idea for the present study originated from the paper by Haldoupis and Pancheva (2002) who suggested that $E_{\text {s }}$ observational data can be useful for inferring information on PW. Haldoupis and Pancheva have computed estimates for the propagation direction, zonal wave number, and phase velocity of the 7-day PW by analyzing $f_{\mathrm{o}} E_{\mathrm{s}}$ data from eight ionosonde stations. $E_{\mathrm{s}}$ observational data should have a global response with the occurring $\mathrm{PW}$ given that convincing experimental evidence showed that $\mathrm{PW}$ have a profound role in the physics of midlatitude $E_{\mathrm{s}}$ and they have 

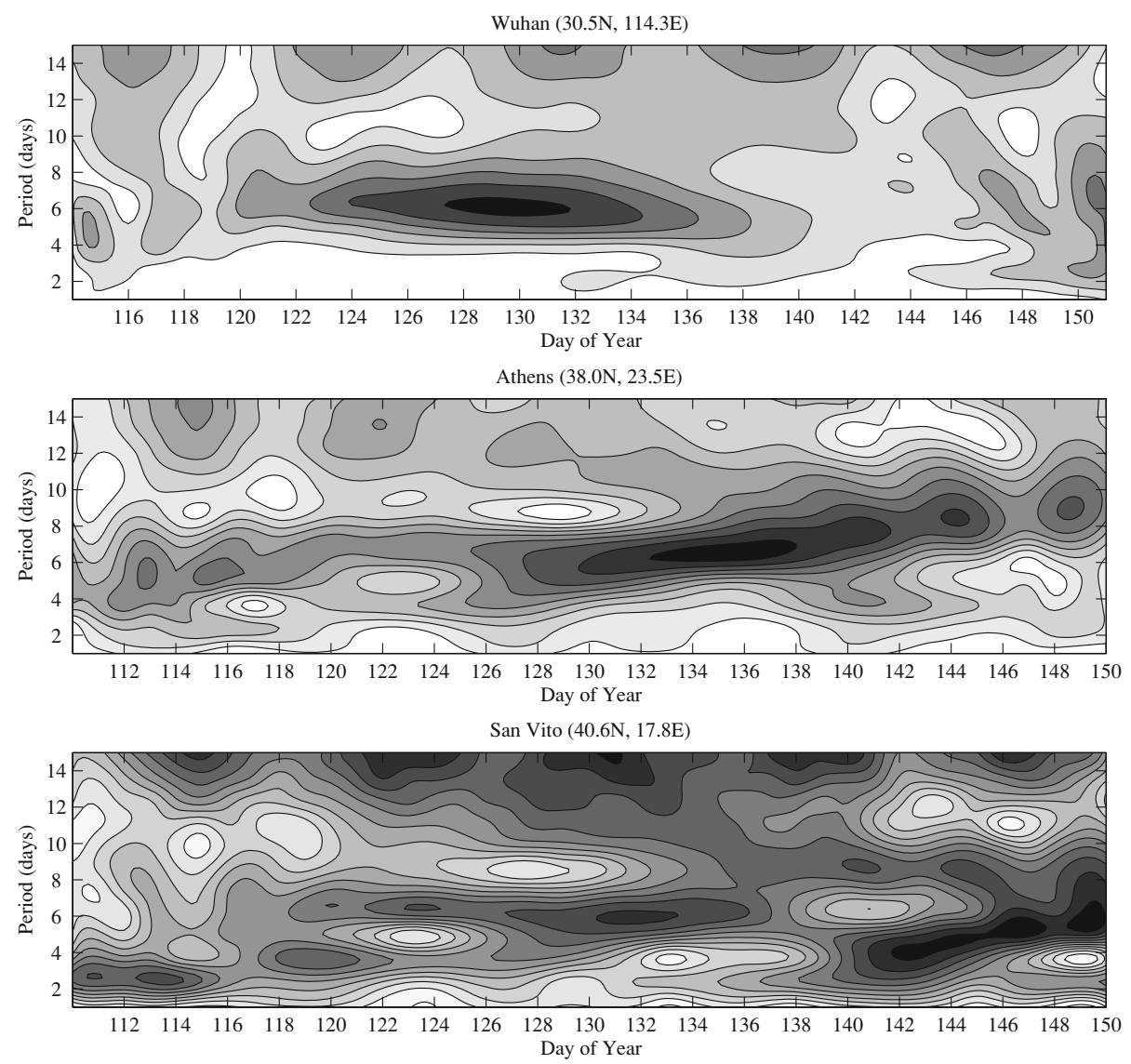

Fig. 1. Wavelet spectrograms for the time series of $E_{\mathrm{s}}$ occurrence during the period from day 110 to 150 of 2003 at Wuhan, Athens and San Vito.

global scales, although PWs are confined inside a limited altitude range in the MLT region. In the present study the observational data of $E_{\mathrm{s}}$ at different stations located in different areas were analyzed to provide further evidence of long-period disturbance exist in the $E_{\mathrm{s}}$ occurrence. Moreover, we also attempted to infer PW information utilizing ionogram $E_{\mathrm{s}}$ data following the methods in Haldoupis and Pancheva's paper (2002). The results argued the existence of a close relationship between PW and midlatitude $E_{\mathrm{s}}$, and provided new support to the option of using the abundance of global $E_{\mathrm{s}}$ measurements in studying PW characteristics and dynamics.

\section{The 6-day Planetary Wave Oscillations Occur- ring during May 2003}

Quasi 6-day oscillation in $E_{\mathrm{s}}$ occurrence was observed to occur during May 2003 in relation with planetary wave activity at Wuhan, China $\left(30.6^{\circ} \mathrm{N}, 114.5^{\circ} \mathrm{E}\right)$, as reported by Zuo and Wan (2008), who also found the same quasi 6-day planetary wave oscillation dominates the spectrum of concurrent wind data measured in the $80-100 \mathrm{~km}$ region by the meteor radar located also at Wuhan. The strong wave with quasi 6-day period in May 2003 has been also observed by the sounding of the atmosphere using broadband emission radiometry (SABER) instrument aboard the thermosphereionosphere-mesosphere energetics and dynamics (TIMED) satellite (Riggin et al., 2006). Thus, this event with large amplitude and long duration was a typical global PW oscillation.
Since PWs have global scales and propagate approximately in zonal direction, we inspected $E_{\mathrm{s}}$ observational data at other stations locating in the latitudinal zone from 20 to 40 degree to examine if exist synchronous long periodicity oscillations. As expected, quasi 6-day planetary wave oscillations were found to occur in $E_{\mathrm{s}}$ occurrence at Athens $\left(38.0^{\circ} \mathrm{N}, 23.5^{\circ} \mathrm{E}\right)$ and San Vito $\left(40.6^{\circ} \mathrm{N}, 17.8^{\circ} \mathrm{E}\right)$ station locating in the European sector during the same period.

Following the method of Zuo and Wan (2008), we first obtained the daily occurrence of $E_{\mathrm{s}}$ layers (for conditions when $f_{\mathrm{o}} E_{\mathrm{s}}>5 \mathrm{MHz}$ ) at Wuhan, Athens and San Vito. The continuous Morlet wavelet analysis (e.g., Torrence and Compo, 1998) was then applied to the time series of $E_{\mathrm{s}}$ occurrence for the period from day 110 to 150 of year 2003, when $E_{\mathrm{s}}$ occurrence was fairly continuous. Figure 1 displays the period time spectrograms of the three stations. As shown in the figure, quasi 6-day (5 7-day) oscillations can be seen clearly at all stations. The oscillations were present for the time interval from about day 123 to 136 at Wuhan, day 126 to 142 at Athens and day 127 to 137 at San Vito. The results reveal that a strong 6-day periodicity occurred approximately concurrently in $E_{\mathrm{s}}$ at the three stations.

In order to investigate the PW oscillations in the $E_{\mathrm{s}}$ occurrence in details, the time sequences of daily $E_{\mathrm{s}}$ occurrence for the three stations during the period from day 110 to 141 of year 2003, when the pronounced 6-day oscillations occurred, are shown in Fig. 2. It is immediately obvious that $E_{\mathrm{s}}$ occurrence at Wuhan is much higher than that at Athens and San Vito, which is subject to the "Far East 


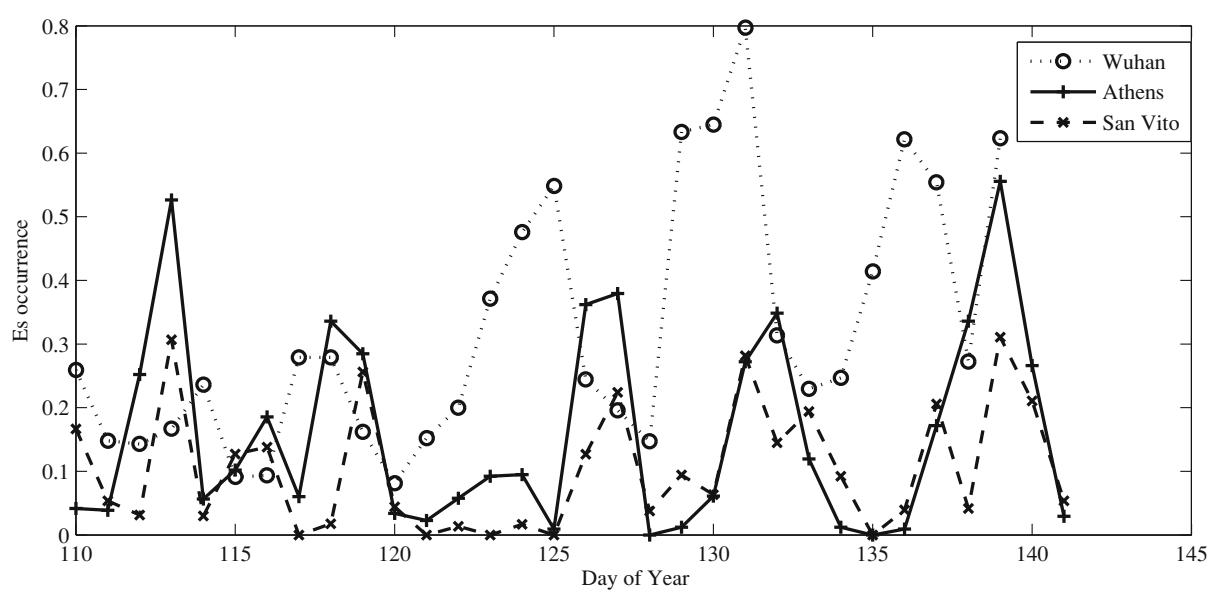

Fig. 2. Time sequences of $E_{\mathrm{s}}$ occurrence for the time interval from day 110 to 141 of 2003 at Wuhan, Athens and San Vito.

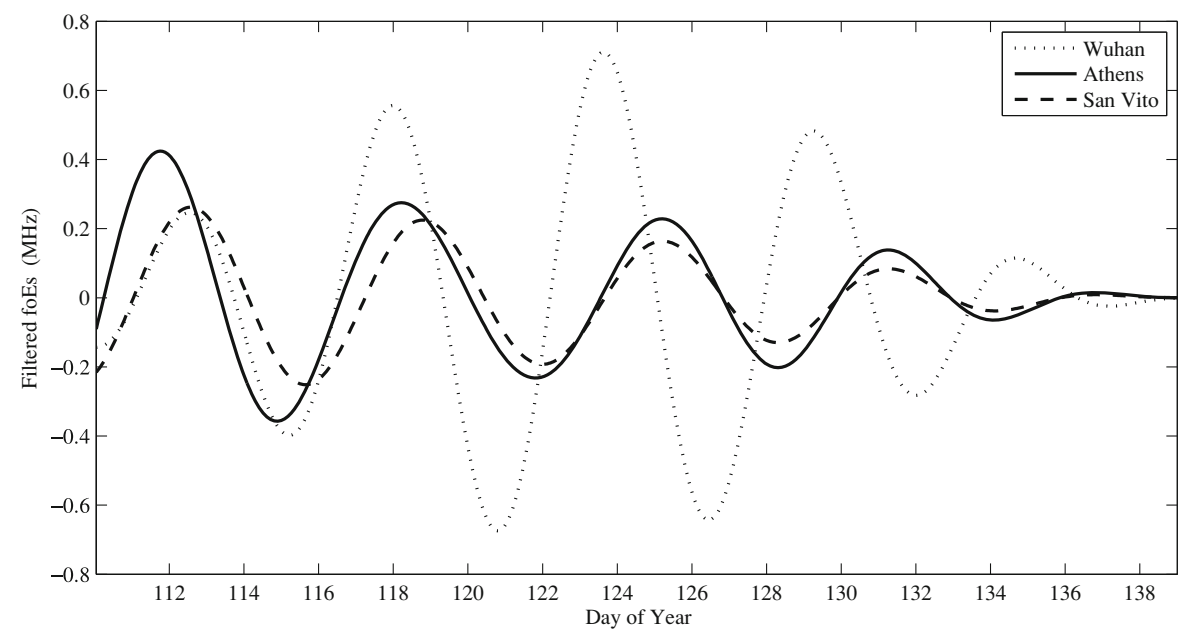

Fig. 3. The quasi 6-day band-pass-filtered hourly $f_{\mathrm{o}} E_{\mathrm{s}}$ time series for the period from day 110 to 139 of 2003 at Wuhan, Athens and San Vito.

Table 1. Cross-correlation analysis for the filtered signals shown in Fig. 3.

\begin{tabular}{lcccc}
\hline Station pairs & Correlation coefficient & Time lag $(\mathrm{h})$ & Zonal wave number & Phase velocity $(\mathrm{m} / \mathrm{s})$ \\
\hline Wuhan-Athens & 0.9256 & -43 & 1.18 & 51.6 \\
Athens-San Vito & 0.9682 & -1 & $\backslash$ & $\backslash$ \\
Wuhan-San Vito & 0.8863 & -43 & 1.11 & 53.4 \\
\hline
\end{tabular}

Anomaly" (e.g., Smith, 1957). Note that there is a close coincidence between the two time sequences for Athens and San Vito with a linear correlation coefficient 0.68 , as is expected since Athens is close to San Vito. In addition, $E_{\mathrm{s}}$ occurrence at Wuhan also showed a coherent pattern with those at Athens and San Vito, but there was time shift with 2-3 days in $E_{\mathrm{s}}$ occurrence between Wuhan and other two stations. We estimated that the maximum correlation coefficient about 0.73 when the time lag is 2 days by applying cross-correlation analysis. This analysis reveals that the 6day PW oscillations in $E_{\mathrm{s}}$ occurrences at Athens and San Vito are almost synchronous but lag behind that at Wuhan since the longitudinal separation between them is as large as $100^{\circ}$. The phase shift between the two stations and Wuhan indicates the westward propagation direction for the 6-day wave.

In the following we use two methods to estimate the wave propagation properties and zonal wave number (ZWN) by analyzing the $f_{\mathrm{o}} E_{\mathrm{s}}$ data.

The First, a three-order Butterworth band-pass filter, which was centered on 6 days with a full width of 3 days, was performed on the $f_{\mathrm{o}} E_{\mathrm{s}}$ time series for the three stations. The filter outputs are shown in Fig. 3. As depicted in Fig. 3, the 6-day wave oscillations occurred clearly at all stations, with the strongest amplitude appearing at Wuhan. In addition, the 6-day waves for Athens and San Vito are almost in phase, while phase differences are clearly between Wuhan and the other two stations. Cross-correlation analysis was applied to the filtered outputs, and then the cross-correlation coefficient and the time lag (in hours) were obtained. The zonal wave number and the phase velocity of the 6-day PW signature were calculated and the results are summarized in Table 1 for the station pairs. The results are not reliable for the station pair: Athens-San Vito because the two stations 


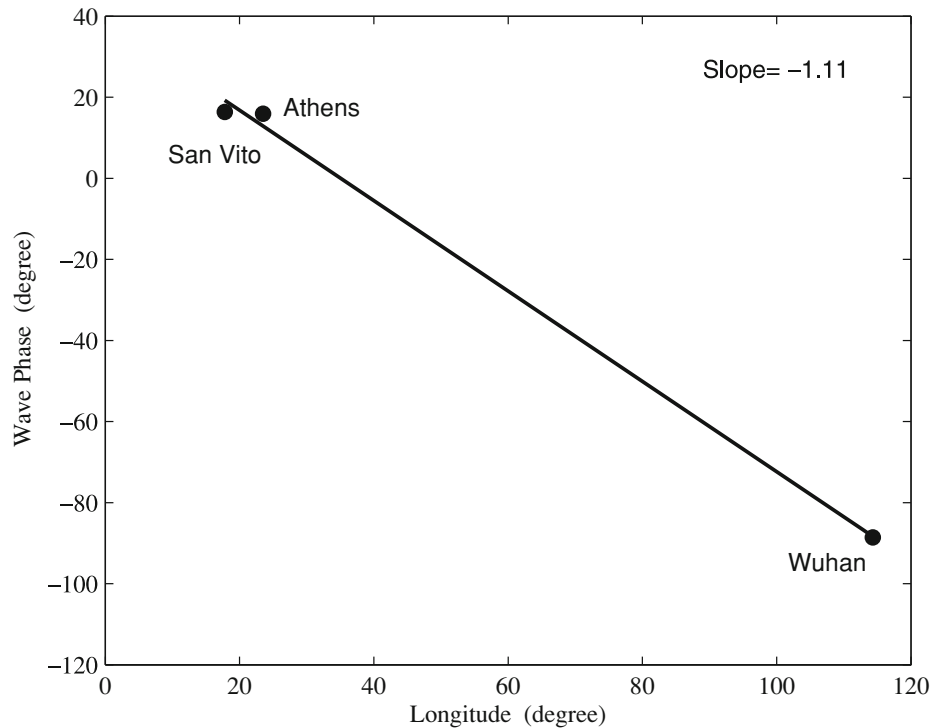

Fig. 4. Wave phase-longitude plot for Wuhan, Athens and San Vito. The slope of the line provides the planetary zonal wave number, where the minus sign means westward propagation.
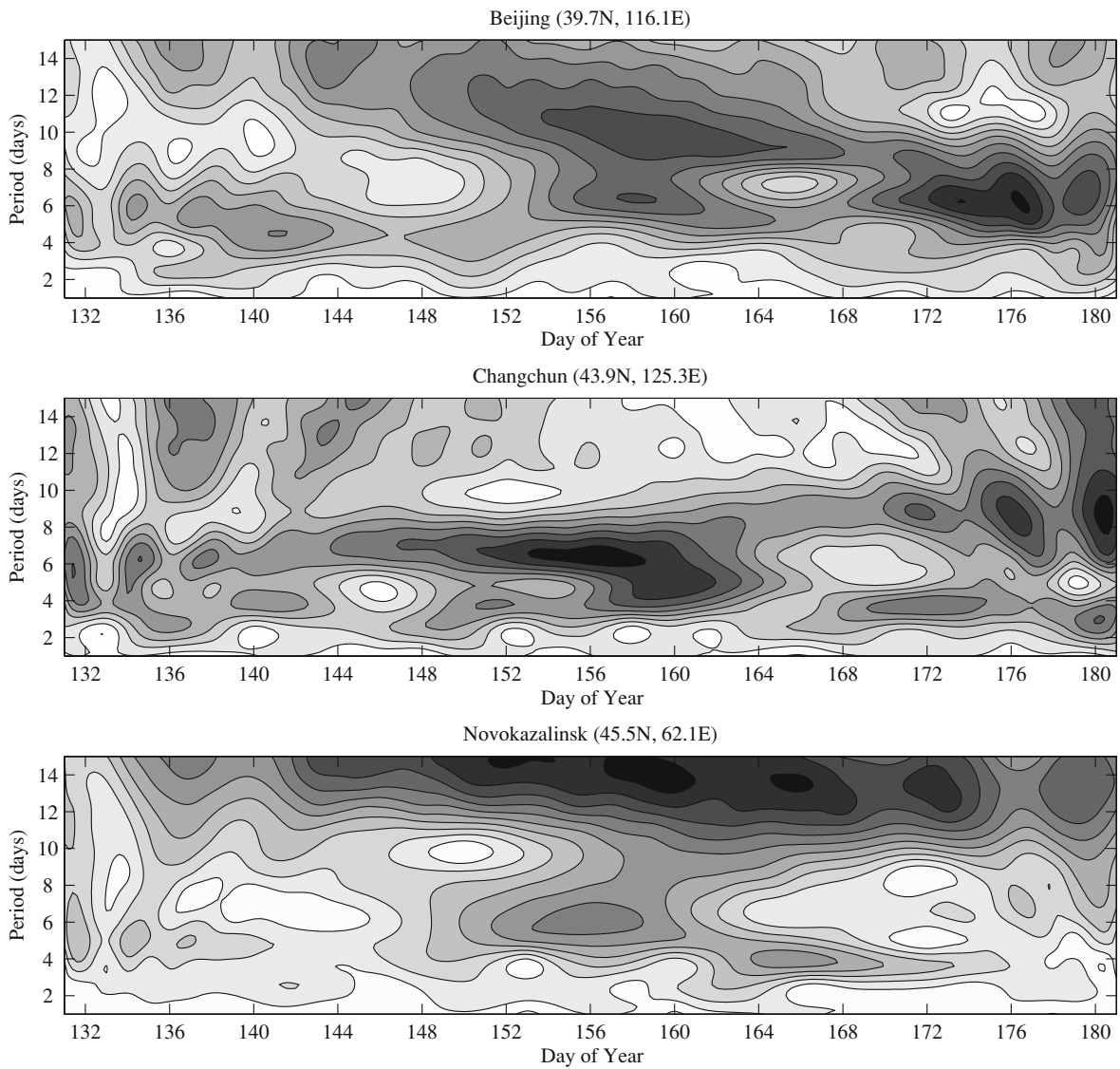

Fig. 5. Wavelet spectrograms for the time series of $E_{\mathrm{s}}$ occurrence during the period from day 131 to 181 of 1970 at Beijing, Changchun and Novokazalinsk.

are too close, and therefore they are not shown in the table. The mean zonal wave numbers was 1.1 and the westward mean phase velocity of the wave was $52 \mathrm{~m} / \mathrm{s}$.

The Second, every $f_{\mathrm{o}} E_{\mathrm{s}}$ time series for the period from day 120 to 139 of year 2003, when the quasi 6-day PW activity was strongest, were analyzed by applying a leastsquare fitting algorithm (e.g., see Hocking et al., 2001 for more details) to estimate the phases of the quasi 6-day PW. Subsequently, following standard methodology applied in PW analysis, the slope of the station points in the "phaselongitude plot" determines the zonal wave number of the propagating wave. The results of this analysis are displayed in Fig. 4. As seen, the zonal wave number is -1.11 (and a standard error 0.06), where the minus sign indicates west- 


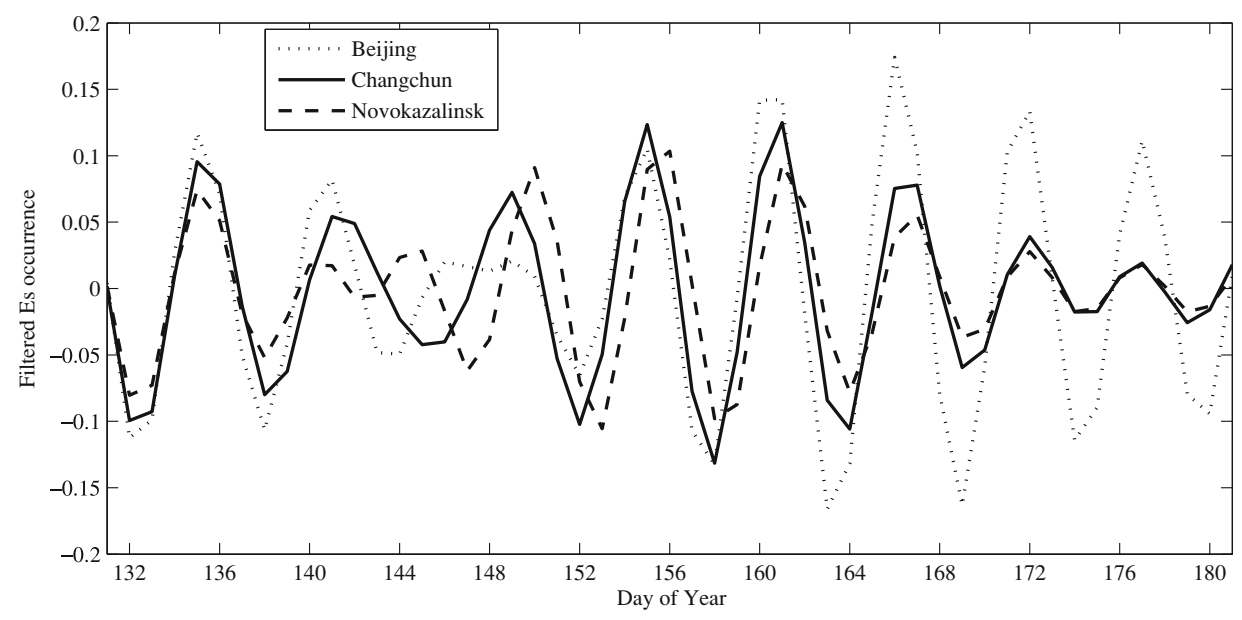

Fig. 6. The quasi 6-day band-pass-filtered daily $E_{\mathrm{s}}$ occurrence time series for the period from day 131 to 181 of 1970 at Beijing, Changchun and Novokazalinsk.

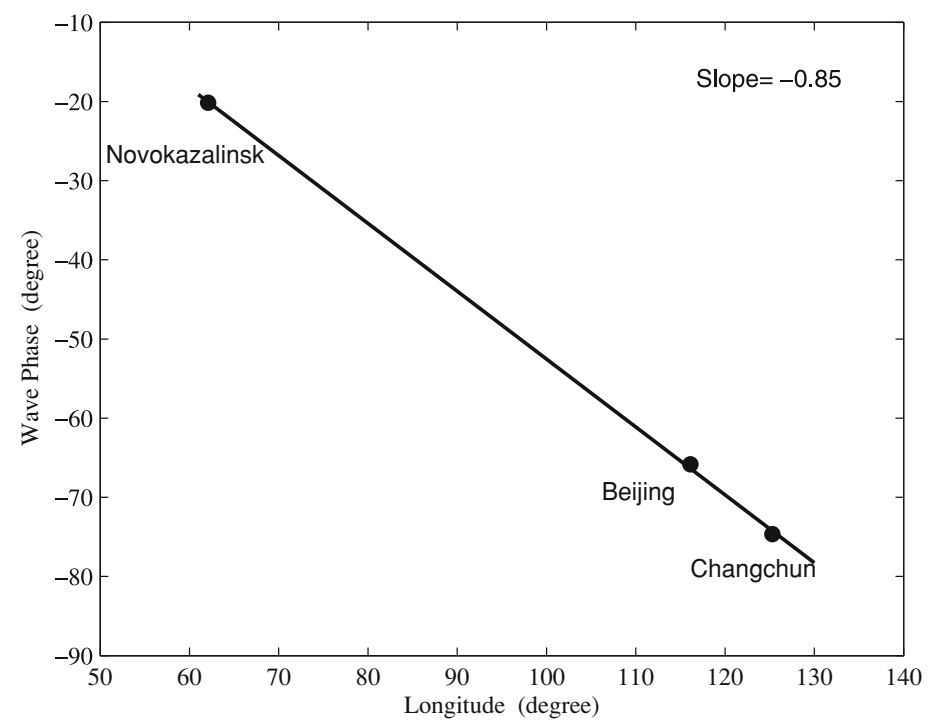

Fig. 7. Wave phase-longitude plot for Beijing, Changchun and Novokazalinsk. The slope of the line provides the planetary zonal wave number, where the minus sign means westward propagation.

ward propagation; the estimated mean phase velocity was $53.4 \mathrm{~m} / \mathrm{s}$.

In summary, the two methods used in the $f_{\mathrm{o}} E_{\mathrm{s}}$ wave analysis provide nearly identical results for the zonal wave number, the propagation direction and the phase velocity of the 6-day wave.

\section{The 6-day Planetary Wave Oscillations Occur- ring during June 1970}

In addition, we also investigated another long periodicity oscillations occurring in $E_{\mathrm{s}}$ during June 1970 . The $f_{\mathrm{o}} E_{\mathrm{s}}$ time series for three stations, Beijing $\left(39.7^{\circ} \mathrm{N}, 116.1^{\circ} \mathrm{E}\right)$, Changchun $\left(43.9^{\circ} \mathrm{N}, 125.3^{\circ} \mathrm{E}\right)$ and Novokazalinsk $\left(45.5^{\circ} \mathrm{N}\right.$, $62.1^{\circ} \mathrm{E}$ ), separating about $60^{\circ}$ longitudinal zone were analyzed. We presumed that $E_{\mathrm{s}}$ was affected by a 6-day planetary wave since strong quasi 6-day oscillations were obviously present in the time series of $f_{\mathrm{o}} E_{\mathrm{s}}$ during the period though no data of radar or satellite measurements can be obtained at that time to prove there is really a global-scale wave occurred. Based on the reasonable assumption, we attempted to infer PW parameters by analysis $E_{\mathrm{s}}$ data following the above methods.

Figure 5 displays the period time spectrograms of the daily $E_{\mathrm{s}}$ occurrence for the period from day 131 to 181 of year 1970 at Beijing, Changchun and Novokazalinsk. Strong quasi 6-day oscillations occurred around day 156 at all stations, with the most pronounced peak at Changchun station. Note that quasi 6-day oscillations were also present around day 142 and day 176 at Beijing. Except the 6-day periodicity, a 10-day periodicity was also present around day 158 at Beijing and a brief 3-day oscillation occurred on day 165 at Novokazalinsk. The band-pass filter outputs, shown in Fig. 6, also reveal that the $E_{\mathrm{s}}$ occurrence manifests a strong quasi 6-day periodicity from day 152 to 168 at all stations, and the strongest peak of $E_{\mathrm{s}}$ occurrence is 0.2 present at Beijing.

Furthermore, the wave propagation properties were estimated utilizing $f_{\mathrm{o}} E_{\mathrm{s}}$ data of the three stations following the methods introduced in Section 2. It should be noted that only the results estimated by using the second method are 
showed here since two methods provided almost identical results for the wave propagation properties. The $f_{\mathrm{o}} E_{\mathrm{s}}$ time series at each stations for the period from day 150 to 170 of year 2003, when the quasi 6-day PW activity was strongest, was analyzed by applying the least-square fitting algorithm to estimate the phase of the quasi 6-day PW. As shown in Fig. 7, the slope of the station points, namely the zonal wave number, is -0.85 with a standard error 0.02. Again, the minus sign indicates westward propagation of the planetary wave. In addition, the estimated mean phase velocity was $64.3 \mathrm{~m} / \mathrm{s}$.

\section{Discussion and Concluding Comments}

We have reported two experimental cases in this study and found that planetary waves play a profound role in sporadic $E$ layers. Two methods were applied to analyze the $f_{\mathrm{o}} E_{\mathrm{s}}$ time series and then to estimate the propagation direction, zonal wave numbers and phase velocities of the 6-day PW. The obtained results are in agreement with those reported from radar and satellite neutral wind MLT measurements (Wu et al., 1994; Clark et al., 2002). More importantly, this work proves the validity of the use of $f_{\mathrm{o}} E_{\mathrm{s}}$ data as an alternative studying means of PW activity. Therefore, $f_{\mathrm{o}} E_{\mathrm{s}}$ time series may be very useful for inferring information on large scale neutral dynamics at altitudes above $100 \mathrm{~km}$, where are usually higher than those covered by conventional (meteor and medium frequency) radar methods. By the way, the analysis methodology has its advantage because of the availability of the global $E_{\mathrm{s}}$ ionosonde network.

Finally, it should be noted that sometimes the long period variability in $E_{\mathrm{s}}$ is probably not to be directly caused by PW and only by the modulated tides, i.e. in case when the tidal amplitude modulation is generated by a nonlinear interaction with the $\mathrm{PW}$ which takes place at stratosphere levels and the generation of the secondary waves is fed by the energy taken from the PW, that is, the PW itself could not penetrate to the MLT region and together with the modulated tides to affect the sporadic $E$ layer variability. If this is the case, the derived PW parameters by analyzing the $E_{\mathrm{s}}$ data may be different from the original zonal structure of the PW. This concern indicates that the application of this approach is limited and more suitable for the case that PW itself is observed in the MLT region.

In conclusion, in view of the very close relation between planetary waves and sporadic $E$ layers, an alternative means of studying PW parameters by analyzing $E_{\mathrm{s}}$ observation data may be used. By the way, we only used the $E_{\mathrm{s}}$ data from three stations for each event in this work. A future study is planned that will investigate the PW activity in the $E_{\mathrm{s}}$ occurrence by collecting global ionosonde observations.
Acknowledgments. This work was supported by National Natural Science Foundation of China (40804039, 40804038).

\section{References}

Clark, R. R., M. D. Burrage, S. J. Franke, A. H. Manson, C. E. Meek, N. J. Mitchell, and H. G. Muller, Observations of 7-d planetary waves with MLT radars and the UARS-HRDI instrument, J. Atmos. Sol.-Terr. Phys., 64, 1217-1228, 2002.

Haldoupis, C. and D. Pancheva, Planetary waves and midlatitude sporadic $E$ layers: Strong experimental evidence for a close relationship, J. Geophys. Res., 107(A6), 1078, doi:10.1029/2001JA000212, 2002.

Haldoupis, C., D. Pancheva, and N. J. Mitchell, A study of tidal and planetary wave periodicities present in midlatitude sporadic E layers, J. Geophys. Res., 109, A02302, doi: 10.1029/2003JA010253, 2004.

Hocking, W. K., B. Fuller, and B. Vandepeer, Real-time determination of meteor related parameters utilizing modern digital technology, J. Atmos Sol.-Terr. Phys., 63, 155-169, 2001.

Mathews, J. D., Sporadic E: Current views and recent progress, J. Atmos. Sol. Terr. Phys., 60, 413-435, 1998.

Pancheva, D., C. Haldoupis, C. E. Meek, A. H. Manson, and N. J. Mitchell, Evidence of a role for modulated atmospheric tides in the dependence of sporadic $E$ layers on planetary waves, J. Geophys. Res., 108(A5), 1176, doi:10.1029/2002JA009788, 2003.

Riggin, D. M., H.-L. Liu, R. S. Lieberman, R. G. Roble, J. M. Russell III, C. J. Mertens, M. G. Mlynczak, D. Pancheva, S. J. Franke, Y. Murayama, A. H. Manson, C. E. Meek, and R. A. Vincent, Observations of the 5-day wave in the mesosphere and lower thermosphere, J. Atmos. Sol.-Terr. Phys., 68, 323-339, 2006.

Shalimov, S. and C. Haldoupis, A model of mid-latitude E-region plasma convergence inside a planetary wave cyclonic vortex, Ann. Geophys., 20, 1193-1201, 2002.

Shalimov, S., C. Haldoupis, M. Voiculescu, and K. Schlegel, Midlatitude $E$ region plasma accumulation driven by planetary wave horizontal wind shears, J. Geophys. Res., 104, 28207-28213, 1999.

Smith, E. K., Worldwide occurrence of sporadic E, U.S. Govt. Printing Office, Washington, D.C., 1957.

Torrence, C. and G. Compo, A practical guide to wavelet analysis, Bull. Am. Meteorol. Soc., 79, 61-78, 1998.

Tsunoda, R. T., M. Yamamoto, K. Igarashi, K. Hocke, and S. Fukao, Quasiperiodic radar echoes from midlatitude sporadic $E$ and role of the 5-day planetary wave, Geophys. Res. Lett., 25, 951-954, 1998.

Voiculescu, M., C. Haldoupis, and K. Schlegel, Evidence for planetary wave effects on midlatitude backscatter and sporadic $E$ layer occurrence, Geophys. Res. Lett., 26, 1105-1108, 1999.

Voiculescu, M., C. Haldoupis, D. Pancheva, M. Ignat, K. Schlegel, and S. Shalimov, More evidence for a planetary wave link with midlatitude E region coherent backscatter and sporadic E layers, Ann. Geophys., 18, 1182-1196, 2000.

Whitehead, J. D., Recent work on mid-latitude and equatorial sporadic $E$, J. Atmos. Terr. Phys., 51, 401-424, 1989.

Wu, D. L., P. B. Hays, and W. R. Skinner, Observations of the 5-day wave in the mesosphere and lower thermosphere, Geophys. Res. Lett., 21, 2733-2736, 1994.

Zuo, X. and W. Wan, Planetary wave oscillations in sporadic $E$ layer occurrence at Wuhan, Earth Planets Space, 60(6), 647-652, 2008.

X. Zuo (e-mail: zuoxiaomin@yahoo.com.cn), W. Wan, and G. Zhao 